\title{
Staurosporine enhances ATRA-induced granulocytic differentiation in human leukemia U937 cells via the MEK/ERK signaling pathway
}

\author{
LEI SHI, XIANG-QIN WENG, YAN SHENG, JING WU, MING DING and XUN CAI \\ Shanghai Institute of Hematology and State Key Laboratory of Medical Genomics, Rui Jin Hospital, \\ Shanghai Jiao Tong University School of Medicine, Shanghai 200025, P.R. China
}

Received April 18, 2016; Accepted September 15, 2016

DOI: $10.3892 /$ or.2016.5123

\begin{abstract}
Although all-trans retinoic acid (ATRA) is regarded as a prominent example of differentiation therapy, it is not effective for the treatment of other subtypes of acute myeloid leukemia (AML) beyond acute promyelocytic leukemia (APL). Therefore, new strategies need to be explored to extend the efficacy of ATRA-based therapy to non-APL AML patients. In the present study, staurosporine, a protein kinase $\mathrm{C}$ (PKC) pan-inhibitor, exhibited synergism with ATRA to promote granulocytic differentiation in poorly ATRA-sensitive U937 cells but not in ATRA unresponsive K562 and Kasumi cells. Staurosporine or the combined treatment did not affect PKC activity in U937 cells. Moreover, other selective PKC inhibitors, UCN-01, Go6976 or rottlerin failed to enhance ATRA-induced granulocytic differentiation in U937 cells. Therefore, staurosporine-enhanced ATRA-induced granulocytic differentiation in U937 cells may be independent of PKC. Staurosporine activated mitogen-activated protein kinase kinase (MEK) and extracellular signal-regulated kinase (ERK). Meanwhile, staurosporine also enhanced ATRA-promoted upregulation of the protein level of CCAAT/enhancer-binding protein $\beta(\mathrm{C} / \mathrm{EBP} \beta)$ and $\mathrm{C} /$ EBPe in U937 cells. Furthermore, blockade of MEK activation suppressed staurosporine-enhanced differentiation as well as the elevated protein level of C/EBPs. Taken together, we concluded that staurosporine enhanced ATRA-induced granulocytic differentiation in U937 cells
\end{abstract}

Correspondence to: Professor Xun Cai, Shanghai Institute of Hematology and State Key Laboratory of Medical Genomics, Rui Jin Hospital, Shanghai Jiao Tong University School of Medicine, 197 Rui Jin Road II, Shanghai 200025, P.R. China

E-mail: xuncai@yahoo.com

Abbreviation: ATRA, all-trans retinoic acid; PKC, protein kinase C; MEK, mitogen-activated protein kinase kinase; ERK, extracellular signal-regulated kinase; C/EBP, CCAAT/enhancer binding protein

Key words: all-trans retinoic acid, differentiation, staurosporine, MEK, U937 via MEK/ERK-mediated modulation of the protein level of C/EBPs.

\section{Introduction}

Acute myeloid leukemia (AML) accounts for approximately $80 \%$ of acute leukemia cases with a median age of 67 years (1). Its incidence is expected to increase with the improvement in life expectancy. In AML patients younger than 60 years, the clinical management is based on high-dose chemotherapy. However, in the majority of AML patients older than 60 years, such chemotherapy is associated with high mortality. Thus, the development of novel and effective anti-AML therapies is urgently required.

Differentiation therapy, which is associated with relatively less severe side effects, may be an alternative to chemotherapy in this circumstance. All-trans retinoic acid (ATRA), a prominent example of differentiation therapy, has been successfully applied in the treatment of acute promyelocytic leukemia (APL) for decades (2). The degradation of promyelocytic leukemia (PML)-retinoic acid receptor (RAR) $\alpha$ fusion protein, the key player in APL leukemogenesis, is widely accepted as one of the important mechanisms of ATRA treatment in APL patients (2). Unfortunately, ATRA-induced differentiation of AML cells has only been observed in APL patients. Since the RA signaling pathway is involved in the regulation of myeloid differentiation and all other AML subtypes express RARs, research approaches that further sensitize cells to ATRA and extend the efficacy of ATRA-based therapy to non-APL AML are being sought. Molecules involved in the epigenetic modulation of the RA signaling pathway have become therapeutic targets of AML. For example, valproic acid (VPA), an inhibitor of histone deacetylase, was found to exhibit a synergistic differentiation-inducing effect with ATRA in an AML cell line and primary AML cells (3). However, clinical trials of VPA combined with ATRA in AML patients did not demonstrate improvement in complete remission (4-6). Inhibition of lysine-specific demethylase 1 by tranylcypromine was shown to unlock the ATRA-triggered differentiation in non-APL AML, suggesting that such epigenetic therapy with ATRA may yield clinical benefit in AML (7). Other approaches which prevented the degradation of RAR $\alpha$ were also demonstrated to 
increase sensitivity to ATRA in ATRA-responsive cell lines, HL-60 and NB4 $(8,9)$.

Staurosporine is a highly potent but non-specific inhibitor of protein kinase $\mathrm{C}$ (PKC), which has demonstrated antitumor activity in a variety of cell lines by inducing apoptosis or differentiation (10-14). Staurosporine was found to synergize with ATRA to trigger granulocytic differentiation in the ATRA-sensitive HL-60 cell line, an AML-M2 cell line with morphology similar to APL cells but without the APL symbol, PML-RAR $\alpha$ fusion protein (15). Moreover, such synergism was also observed in ATRA-resistant APL cell lines (16). Since the differentiation induced by the combined treatment was independent of the PML-RAR $\alpha$ fusion protein in ATRAresistant APL cell lines (16) and such a combination was also effective in one non-APL AML cell line HL-60, we were encouraged to investigate the effect of the combined treatment on other AML cell lines. The AML-M2b cell line Kasumi, erythroleukemia cell line K562 and monocytic leukemia cell line U937 were studied. Staurosporine could not restore ATRA sensitivity in ATRA unresponsive cell lines, K562 and Kasumi. However, it significantly enhanced ATRA-induced granulocytic differentiation and upregulation of CCAAT/ enhancer-binding protein $\beta(\mathrm{C} / \mathrm{EBP} \beta)$ and $\mathrm{C} / \mathrm{EBP} \varepsilon$ in $\mathrm{U} 937$ cells. Both enhanced effects of staurosporine were dependent on mitogen-activated protein kinase kinase (MEK)/extracellular signal-regulated kinase (ERK) activation.

\section{Materials and methods}

Reagents. ATRA was purchased from Sigma-Aldrich (St. Louis, MO, USA). UCN-1, Go6976, rottlerin, staurosporine and U0126 were obtained from EMD Chemicals, Inc. (San Diego, CA, USA). They were all dissolved in dimethyl sulfoxide (DMSO) as a stock solution at $1 \mathrm{mM}, 100 \mu \mathrm{M}$, $100 \mu \mathrm{M}, 2 \mathrm{mM}, 2 \mu \mathrm{M}$ and $10 \mathrm{mM}$, respectively.

Cell culture, cell viability and cell proliferation. U937, K562 and Kasumi cell lines were cultured in RPMI-1640 medium, supplemented with $10 \%$ fetal calf serum (Thermo Fisher Scientific Inc., Waltham, MA, USA) in a humidified atmosphere of $95 \%$ air $/ 5 \% \mathrm{CO}_{2}$ at $37^{\circ} \mathrm{C}$. To avoid possible effects of cell density on cell growth and survival, the cells were maintained at less than $5 \times 10^{5}$ cells $/ \mathrm{ml}$. Cell viability was assessed by trypan-blue exclusion assay. Actual viable cell numbers were calculated by multiplying diluted times with the counted viable cell numbers.

Cell differentiation assays. Cell maturation was evaluated by cellular morphology and the content of cell surface differentiation-related antigen CD11b. Morphology was determined using May-Grünwald-Giemsa staining of cells centrifuged onto slides by cytospin (500 rpm, 5 min; Shandon, Runcorn, UK) and viewed at x1,000 magnification. The expression of cell surface differentiation-related antigen CD11b was determined by flow cytometry (EPICS XL; Beckman Coulter, Hialeah, FL, USA). Fluorochrome-labeled anti-human CD11b/FITC antibodies were purchased from Immunotech (Marseilles, France).

PKC activity assay by ELISA. Detection of PKC activity was performed by ELISA using PKC kinase activity kit (Enzo Life
Sciences, Inc., Farmingdale, NY, USA) according to the manufacturer's instructions. Briefly, the cells were lysed with lysis buffer (20 mM MOPS, 1\% NP-40, 5 mM EGTA, 2 mM EDTA, $1 \mathrm{mM}$ DTT) and cell lysates were centrifuged at 13,000 rpm for $20 \mathrm{~min}$ at $4^{\circ} \mathrm{C}$. Supernatants were collected and quantified by Bio-Rad DC protein assay (Bio-Rad Laboratories, Hercules, CA, USA). Five micrograms of protein extracts together with $10 \mu \mathrm{g}$ ATP were added to PKC substrate microtiter plate and incubated at $30^{\circ} \mathrm{C}$ for $90 \mathrm{~min}$. After washing four times, samples were incubated with phospho-specific substrate antibody followed by horseradish peroxidase (HRP)-conjugated anti-rabbit IgG. Protein binding was quantified by adding TMB substrate and measuring absorbance at $450 \mathrm{~nm}$ in a microplate reader (BioTek Instruments, Inc., Winooski, VT, USA).

Western blot analysis. Cells were washed with phosphate-buffered saline (PBS) twice and lysed with RIPA buffer (Sigma-Aldrich). Cell lysates were centrifuged at 13,000 rpm for $10 \mathrm{~min}$ at $4^{\circ} \mathrm{C}$. Supernatants were collected and quantified by Bio-Rad DC protein assay. Protein extracts were loaded on $8 \%$ SDS-polyacrylamide gel, subjected to electrophoresis, and transferred to polyvinylidene difluoride membranes (GE Healthcare UK Ltd., Buckinghamshire, UK). After blocking with $5 \%$ nonfat milk in PBS, the membranes were probed with antibodies against $\mathrm{C} / \mathrm{EBP} \varepsilon, \mathrm{C} / \mathrm{EBP} \beta$, anti- $\beta$-actin (all from Santa Cruz Biotechnology, Inc., Dallas, TX, USA), phospho-MEK1/2 (Ser217/Try 221) and phospho-p44/42 Erk1/2 (Thr202/Try 204) (Cell Signaling Technology, Inc., Beverly, MA, USA). Then, the membranes were incubated with HRP-conjugated secondary antibody (GE Healthcare UK Ltd.). Immunocomplexes were visualized by a chemiluminescence kit (GE Healthcare UK Ltd.) according to the manufacturer's instructions. To detect Erk1/2 and MEK1/2, the same membrane incubated with the phosphorylated MEK1/2 or Erk $1 / 2$ was stripped with stripping buffer (2\% SDS, $100 \mathrm{mM} \beta$-mercaptoethanol, $50 \mathrm{mM}$ Tris, $\mathrm{pH}$ 6.8) followed by blocking and probing with anti-MEK1/2 or anti-Erk1/2 (both from Cell Signaling Technology, Inc.). The density of the protein band was quantitated using ImageJ software (National Institutes of Health, Bethesda, MD, USA) and expressed as the mean \pm standard deviation (SD) of the relative levels of the objective protein and $\beta$-actin from three independent experiments.

Statistical analysis. For the PKC kinase assay and quantitated analysis of the proteins, a two-tailed unpaired Student's t-test was used. The flow cytometric analysis of CD11b was analyzed by Chi-square test $\left(\chi^{2}\right)$.

\section{Results}

Staurosporine enhances ATRA-induced granulocytic differentiation in U937 cells. To investigate the effect of the combined treatment of staurosporine and ATRA on K562, Kasumi and U937 cells, we first tested the concentration of staurosporine studied in these cell lines. Five nanomoles of staurosporine was used to treat the $\mathrm{K} 562$ cells while $2 \mathrm{nM}$ was applied to treat the Kasumi and U937 cells since they were the maximum concentrations with no obvious effects on cell proliferation and survival in these cell lines for $72 \mathrm{~h}$ (data not shown). The 
A
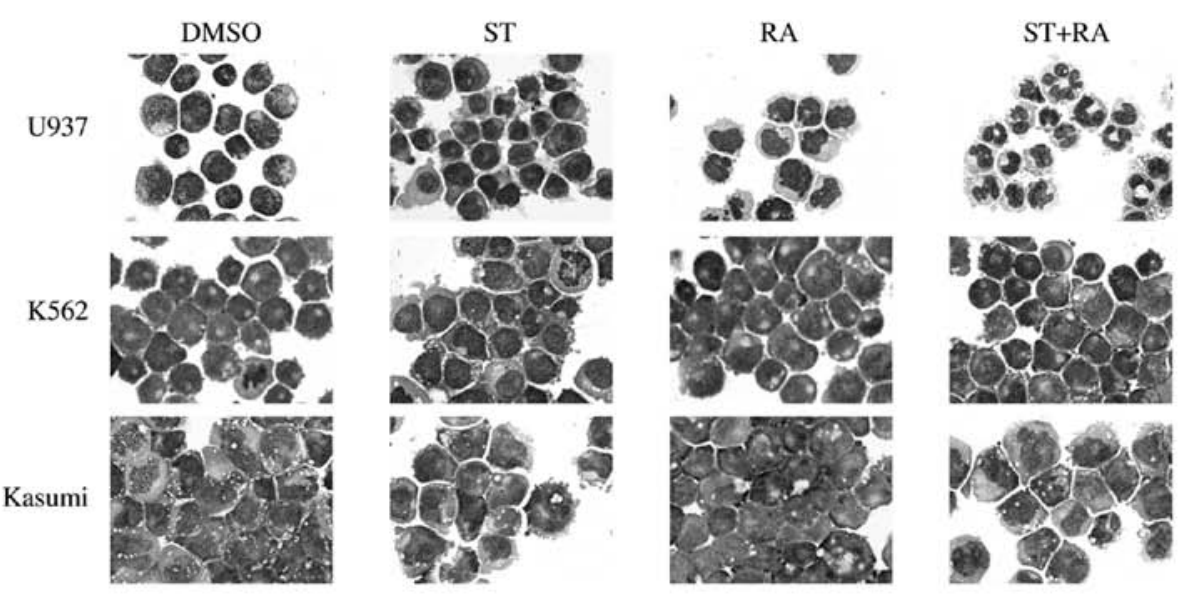

B
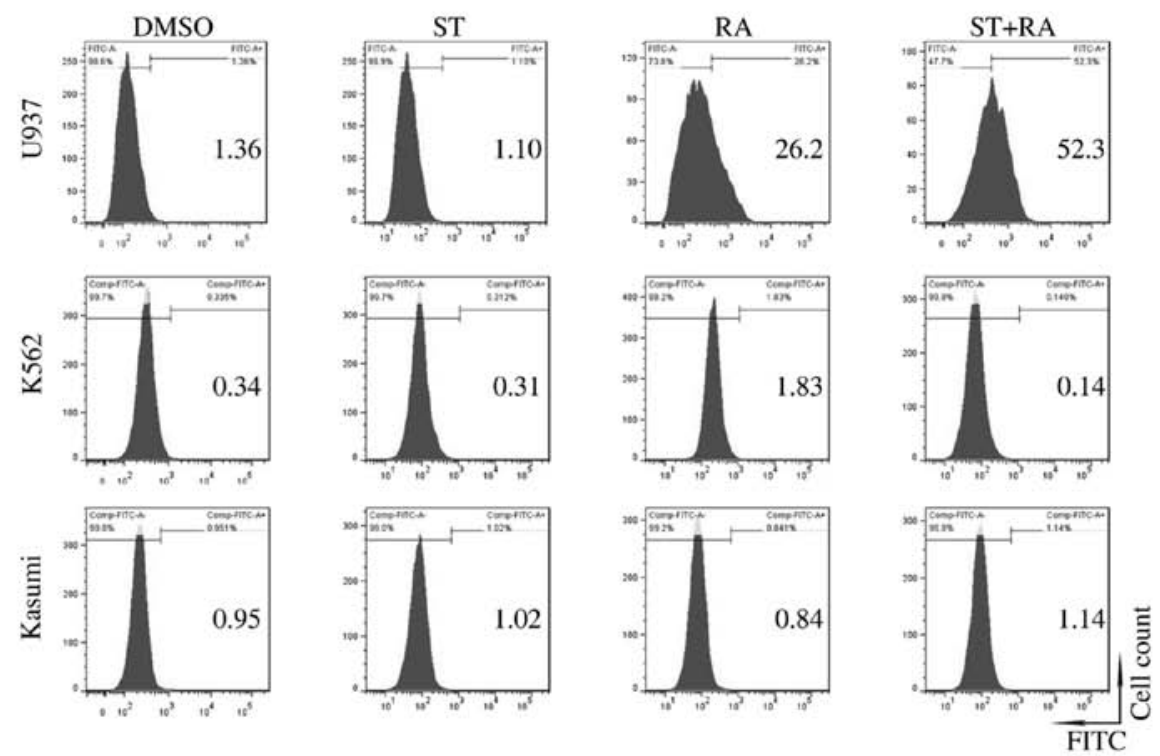

C

D

$\mathbf{E}$
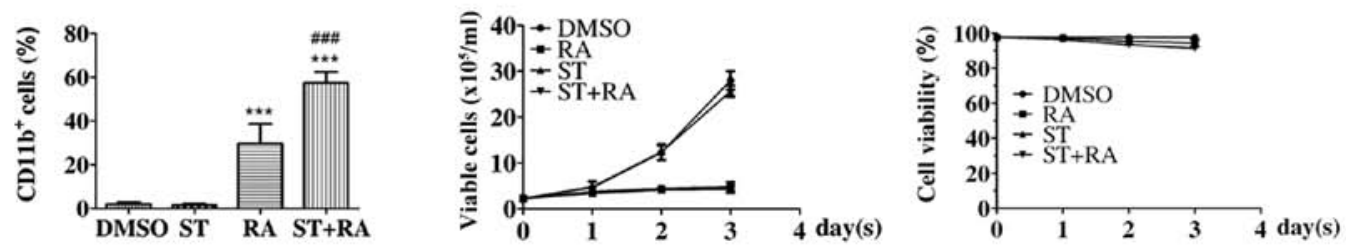

Figure 1. Staurosporine promotes all-trans retinoic acid (ATRA)-induced granulocytic differentiation in U937 cells. (A) One representative image of the morphologic analysis of U937, K562 and Kasumi cells treated with staurosporine (ST) or/and ATRA (RA) for $72 \mathrm{~h}$. Magnification, x1,000. Similar results were obtained in three independent experiments. (B) The representative histogram of flow cytometric analysis of CD11b expression in U937, K562 and Kasumi cells

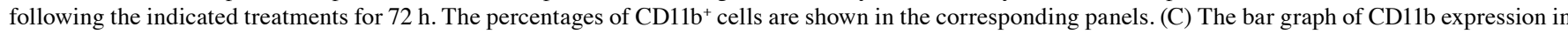
U937 cells for three independent experiments with the indicated treatments for $72 \mathrm{~h}$. Each value represents the mean \pm SD of three independent measurements. ${ }^{* * * *} \mathrm{P}<0.001$ vs. DMSO treated cells. ${ }^{\# \# \# ~} \mathrm{P}<0.001$, indicates a significant difference between RA and ST+RA. (D) Cell growth and (E) viability of U937 cells treated with the indicated drugs were assessed as described in Materials and methods. One representative experiment is shown. Each value represents the mean \pm SD of triplicate samples. Similar results were obtained in three independent experiments.

corresponding DMSO concentrations were regarded as solvent controls since both ATRA and staurosporine were dissolved in it.

The cells were treated with $1 \mu \mathrm{M}$ ATRA and the corresponding concentration of staurosporine for $72 \mathrm{~h}$. Parental U937 cells presented irregular nuclei and a high nuclear/ cytoplasm ratio, which was almost retained in the cells treated with $2 \mathrm{nM}$ staurosporine (Fig. 1A, upper panel). After $1 \mu \mathrm{M}$ ATRA treatment for $72 \mathrm{~h}$, cells with decreased nuclear/ cytoplasm ratio and kidney-shaped nuclei were observed.
Following the combined treatment of $2 \mathrm{nM}$ staurosporine and $1 \mu \mathrm{M}$ ATRA for $72 \mathrm{~h}$, cells displayed the appearance of matured granulocytes, such as lobed nuclei accompanied by markedly decreased nuclear/cytoplasm ratio (Fig. 1A, upper panel). However, no significant morphological change was presented in the K562 or Kasumi cells with either ATRA treatment or the combined treatment for $72 \mathrm{~h}$ (Fig. 1A, middle and lower panels). There was also no marked alteration in the population of $\mathrm{CD}_{11 \mathrm{~b}^{+}}$cells in these two cell lines following these treatments (Fig. 1B, middle and lower panels). As shown 
A

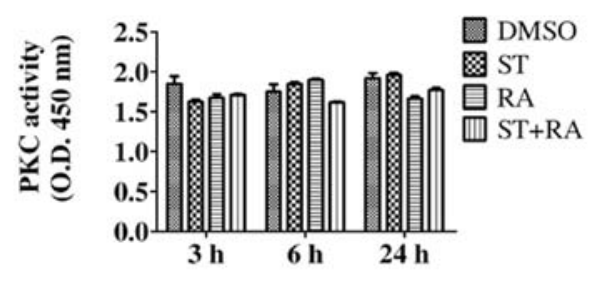

B

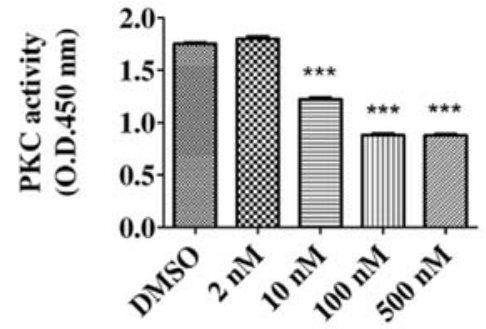

C
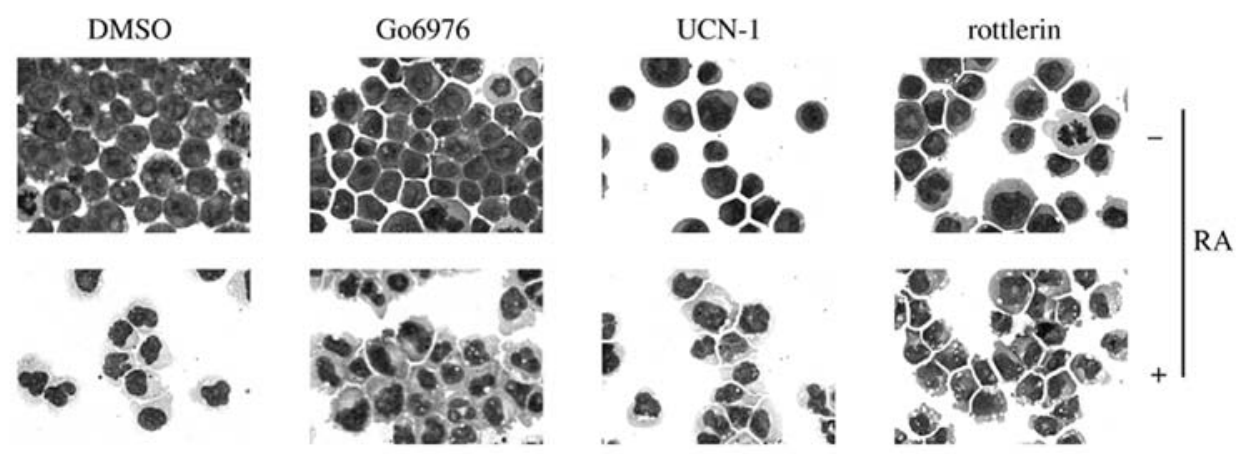

D DMSO

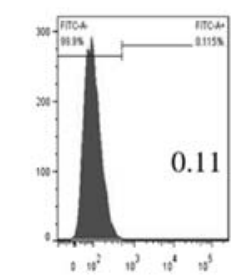

Go6976

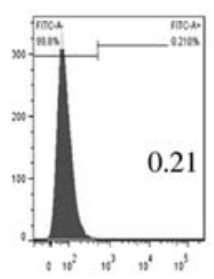

UCN-1

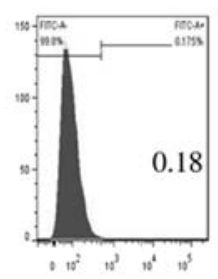

rottlerin
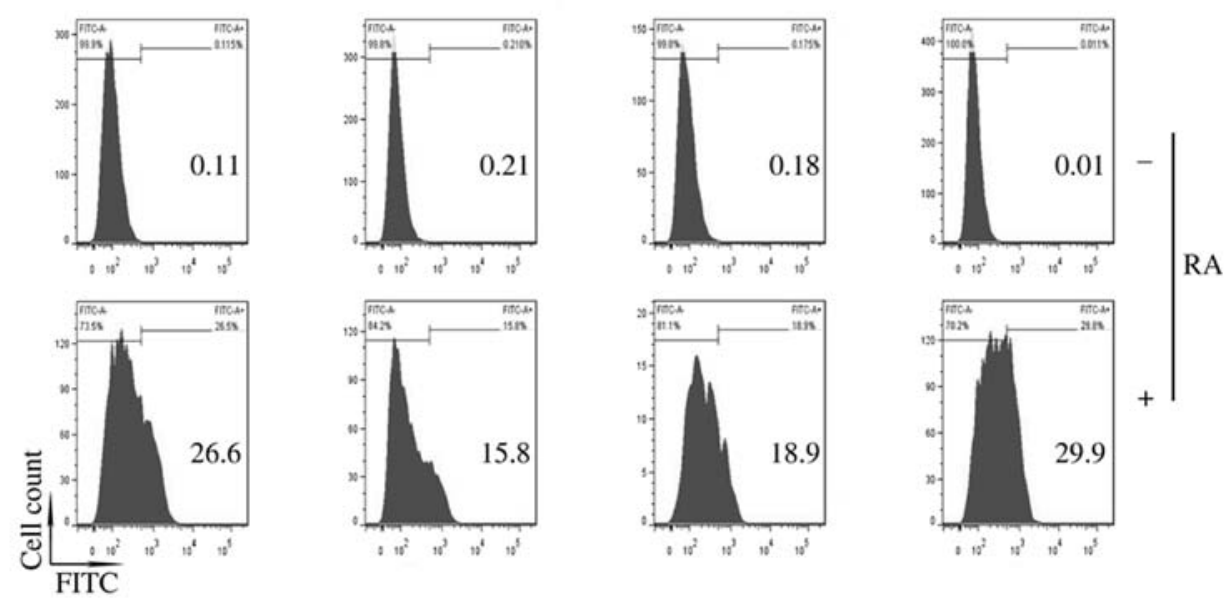

Figure 2. Assessment of protein kinase C (PKC) signaling. (A and B) PKC activity was assessed by ELISA as described in Materials and methods. One representative experiment is shown. Each value represents the mean \pm SD of triplicate samples. Similar results were obtained in three independent experiments. (A) Cells were treated with $1 \mu \mathrm{M}$ all-trans retinoic acid (ATRA) (RA) and/or $2 \mathrm{nM}$ staurosporine (ST) for the indicated times. (B) Cells were incubated with the indicated concentrations of staurosporine for $6 \mathrm{~h} .{ }^{* * *} \mathrm{P}<0.001$ vs. DMSO-treated cells. (C) One representative image of the morphologic analysis of cells treated with other PKC inhibitors or/and ATRA (RA) for $72 \mathrm{~h}$. Magnification, x1,000. Similar results were obtained in three independent experiments. (D) The representative histogram of flow cytometric analysis of CD11b expression in cells treated with other PKC inhibitors and ATRA (RA) for $72 \mathrm{~h}$. The percentages of $\mathrm{CD} 11 \mathrm{~b}^{+}$cells are shown in the corresponding panels. Similar results were obtained in three independent experiments.

in Fig. 1B and C, consistent with the morphological change,

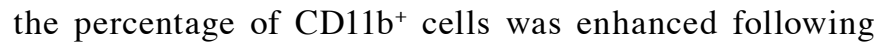
ATRA treatment in the U937 cells (RA compared with DMSO, $29.6 \pm 3.2$ vs. $\left.2.0 \pm 0.5 \%, \chi^{2}=2877.1, \mathrm{P}<0.001\right)$. Although staurosporine treatment alone did not elevate the percentage of

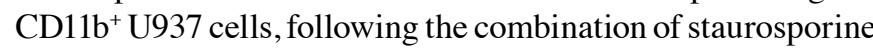
and ATRA, a more than additive effect was observed. The percentage of CD11b ${ }^{+}$U937 cells was significantly increased following the combined treatment (ST+RA compared with DMSO, $57.3 \pm 2.9$ vs. $2.0 \pm 0.5 \%, \chi^{2}=7347.3, \mathrm{P}<0.001 ; \mathrm{ST}+\mathrm{RA}$ compared with RA, 57.3 \pm 2.9 vs. $29.6 \pm 3.2 \%, \chi^{2}=1561.4, \mathrm{P}<0.001$; Fig. 1B and C). However, the percentage of CD14 ${ }^{+}$U937 cells was not altered with either ATRA or the combined treatment (data not shown). Thus, it was demonstrated that staurosporine enhanced ATRA-induced granulocytic differentiation in the U937 cells but not in the ATRA-unresponsive K562 and Kasumi cells. Meanwhile, staurosporine neither suppressed cell proliferation nor affected ATRA-inhibited cell growth in the U937 cells (Fig. 1D). The cell viability was maintained above $90 \%$ with any treatment for $72 \mathrm{~h}$ (Fig. 1E).

Staurosporine-enhanced ATRA-induced granulocytic differentiation in U937 cells is independent of PKC. To explore the mechanisms of the enhanced effect of staurosporine on ATRA-induced differentiation in U937 cells, we first examined the role of PKC since staurosporine is a potent PKC inhibitor with $\mathrm{IC}_{50}$ value of $2.7 \mathrm{nM}$ in an isolated enzyme assay (10), a slightly higher concentration than we used in this study. As 
A

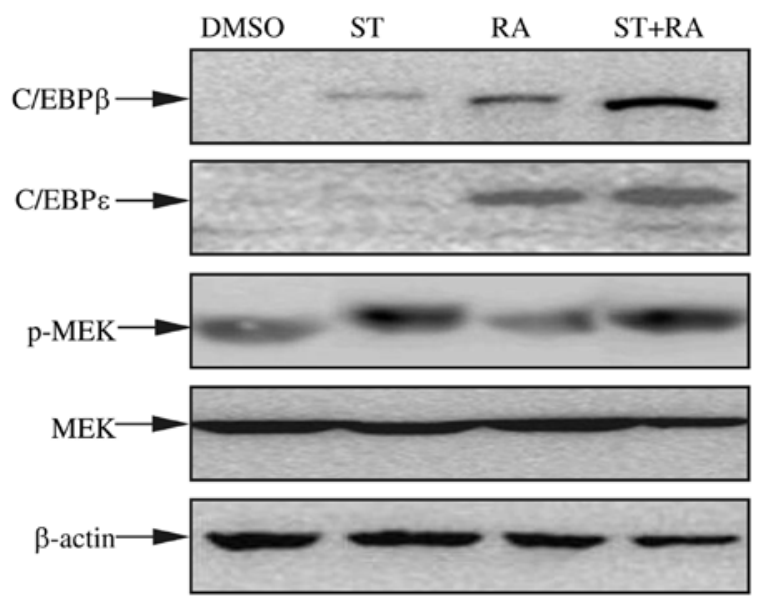

B
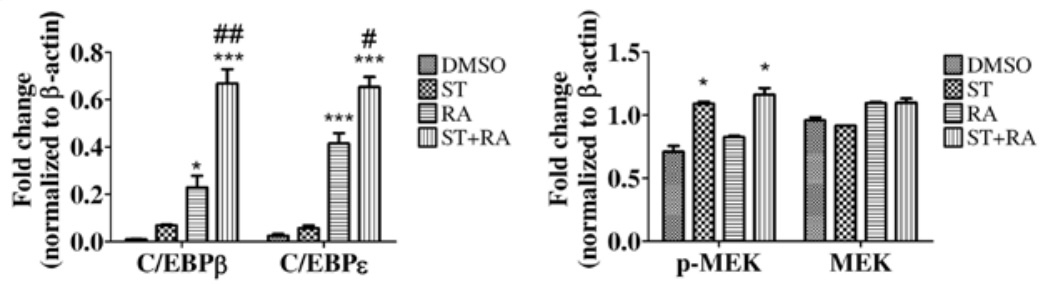

Figure 3. Staurosporine activates mitogen-activated protein kinase kinase (MEK) and enhances the upregulated protein levels of CCAAT/enhancer-binding protein $\beta(\mathrm{C} / \mathrm{EBP} \beta)$ and $\mathrm{C} / \mathrm{EBP} \varepsilon$ by all-trans retinoic acid (ATRA). (A) Protein levels were detected by western blot analysis. Cells were treated with $2 \mathrm{nM}$ staurosporine (ST), $1 \mu \mathrm{M}$ ATRA(RA) alone and the combined treatment (ST+RA) for $24 \mathrm{~h}$. Expression of $\beta$-actin was assessed as internal control. (B) Quantitated analysis of proteins in the U937 cells treated with $2 \mathrm{nM}$ staurosporine (ST) and/or ATRA (RA) for $24 \mathrm{~h}$. Values are expressed as protein/ $\beta$-actin. The data are expressed as mean \pm SD of three experiments. ${ }^{*} \mathrm{P}<0.05,{ }^{* * *} \mathrm{P}<0.001$ vs. DMSO-treated cells. ${ }^{\#} \mathrm{P}<0.05$, ${ }^{\# \#} \mathrm{P}<0.01$, indicate a significant difference between $\mathrm{RA}$ and ST+RA.

shown in Fig. 2A, compared with the PKC activity noted in the DMSO-treated cells, a similar level of PKC activity was detected following treatment with $2 \mathrm{nM}$ staurosporine or the combined treatment. Staurosporine did inhibit PKC activity in the U937 cells only at concentrations of $10 \mathrm{nM}$ or higher after a 6-h incubation (Fig. 2B). However, as mentioned above, $2 \mathrm{nM}$ was the maximum concentration of staurosporine that could be applied in this study. Therefore, $2 \mathrm{nM}$ staurosporine or the combined treatment had no effect on PKC activity.

U937 cells express PKC- $\beta$ I, $-\beta \mathrm{II},-\delta,-\varepsilon$ and $-\zeta$ isoforms (17). To further confirm the role of PKC, we evaluated whether the combination of ATRA with several selective PKC inhibitors could mimic the effect of staurosporine on ATRA-induced differentiation in U937 cells. Go6976 (an inhibitor of PKC- $\alpha$, $-\beta \mathrm{I}$ and $-\mu$ isoforms), UCN-01 (an inhibitor of PKC- $\alpha,-\beta,-\gamma$, $-\delta$, and $-\varepsilon$ isoforms) and rottlerin (an inhibitor of PKC $-\delta,-\alpha,-\beta$, $-\gamma,-\varepsilon$ and $-\zeta$ isoforms) were used in the following experiment. Compared with ATRA treatment alone, no more matured cells were observed following the combined treatment of ATRA and any of the above selective PKC inhibitors (Fig. 2C). CD11b ${ }^{+}$ cells were slightly increased by the combined treatment of rottlerin and ATRA while Go6976 or UCN-01 decreased the

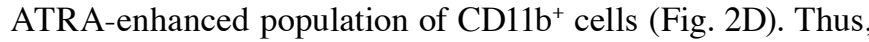
these selective PKC inhibitors did not enhance ATRA-induced differentiation in the U937 cells. Therefore, it was suggested that staurosporine-enhanced ATRA-induced granulocytic differentiation in U937 cells may be independent of PKC.

Staurosporine activates MEK/ERK and enhances ATRA-promoted upregulation of $C / E B P S$. To further investigate the molecular mechanisms of the enhanced effect of staurosporine on ATRA-induced differentiation in U937 cells, we focused on certain proteins or signaling pathways involving in granulocytic differentiation. First, we examined the protein level of $\mathrm{C} / \mathrm{EBP} \beta$ and $\mathrm{C} / \mathrm{EBP} \varepsilon$ by immunoblotting. The induction of $\mathrm{C} / \mathrm{EBP} \beta$ and $\mathrm{C} / \mathrm{EBP} \varepsilon$ expression is implicated in the later stage of granulocytic differentiation $(18,19)$. Moreover, $\mathrm{C} / \mathrm{EBP} \beta$ and $\mathrm{C} / \mathrm{EBP} \varepsilon$ were demonstrated to be required for ATRA-mediated differentiation in APL cells $(20,21)$. Therefore, U937 cells were treated with $2 \mathrm{nM}$ staurosporine, $1 \mu \mathrm{M}$ ATRA, or the combined treatment for $24 \mathrm{~h}$. As shown in Fig. 3, ATRA enhanced the protein levels of both $\mathrm{C} / \mathrm{EBP} \beta$ and $\mathrm{C} / \mathrm{EBP} \varepsilon$ while staurosporine only slightly elevated the $\mathrm{C} /$ $\mathrm{EBP} \beta$ protein level but not $\mathrm{C} / \mathrm{EBP} \varepsilon$. However, with the addition of staurosporine to ATRA treatment, the upregulation of $\mathrm{C} / \mathrm{EBP} \beta$ and $\mathrm{C} / \mathrm{EBP} \varepsilon$ was more marked (Fig. 3).

Activation of MEK/ERK was demonstrated to be required for some cytokine-induced myeloid differentiation as well as ATRA-triggered granulocytic differentiation in APL cells (22-26). To explore whether the MEK/ERK signaling pathway was activated, phosphorylated MEK and ERK1/2 were assessed by western blot analysis in cells treated with $1 \mu \mathrm{M}$ ATRA or/and $2 \mathrm{nM}$ staurosporine for $24 \mathrm{~h}$. As shown in Figs. 3 and 4A, staurosporine but not ATRA increased the amount of phosphorylation of MEK and ERK1/2. Similar levels of phosphorylated MEK and ERK1/2 were detected following the combined treatment. The total amount of MEK and ERK1/2 in both cell lines remained almost unaltered. Therefore, only staurosporine could activate the MEK/ERK signaling pathway. 
A
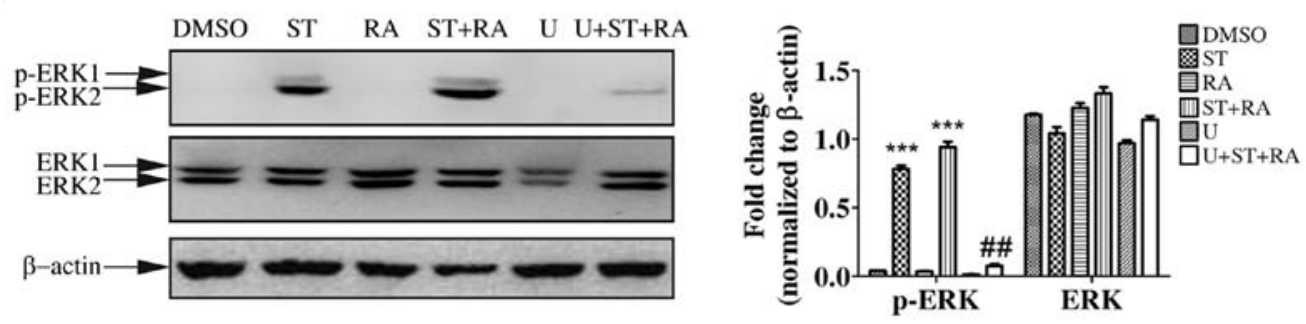

B
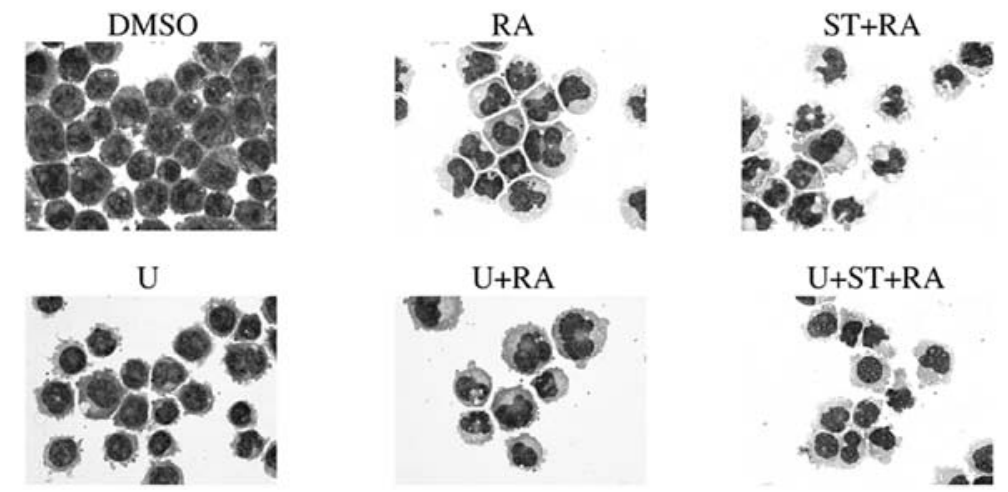

C

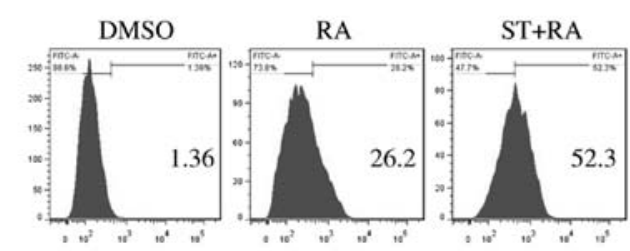

D
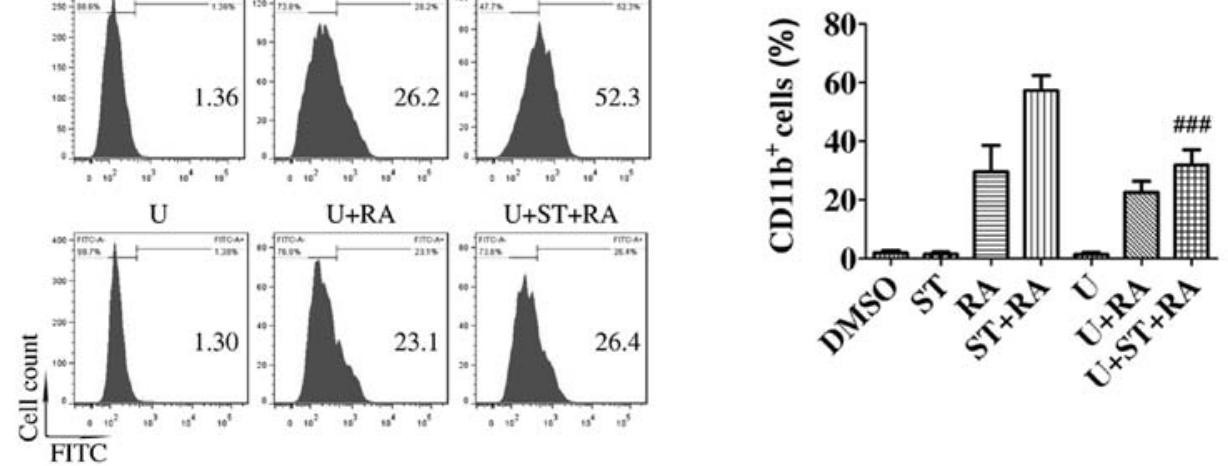

Figure 4. Inhibition of mitogen-activated protein kinase kinase (MEK) activation blocks the enhanced differentiation effect of staurosporine on all-trans retinoic acid (ATRA)-induced granulocytic differentiation. Cells were exposed to $10 \mu \mathrm{M} \mathrm{U} 0126 \mathrm{for} 1 \mathrm{~h}$ prior to other treatments. (A) The attenuation of MEK activation by U0126 (U) was measured by western blot analysis of phosphorylated extracellular signal-regulated kinase (ERK)1/2 in U937 cells with the indicated treatments for $24 \mathrm{~h}$ (left panel). Expression of $\beta$-actin was assessed as internal control. Quantitated analysis of p-ERK and ERK was expressed as protein $/ \beta$-actin (right panel). The data are expressed as mean $\pm \mathrm{SD}$ of three experiments. ${ }^{* * *} \mathrm{P}<0.001 \mathrm{vs.}$. DMSO-treated cells. ${ }^{\# *} \mathrm{P}<0.01$, indicates a significant difference between ST+RA and U+ST+RA. (B) Inhibitory effect of U0126 on morphologic changes in U937 cells incubated with the indicated drugs for $72 \mathrm{~h}$. Magnification, $x 1,000$. One representative experiment among three independent assays is shown. Similar results were obtained in three independent experiments. The inhibitory effect of U0126 on differentiation was also confirmed by flow cytometric analysis of CD11b expression in U937 cells with the indicated drugs for $72 \mathrm{~h}$. (C) One representative histogram of flow cytometric analysis of CD11b expression. The percentages of CD11b cells are shown in the corresponding panels. (D) The bar graph of CD11b expression in U937 cells of three independent experiments with the indicated treatments for $72 \mathrm{~h}$. Each value represents the mean $\pm \mathrm{SD}$ of three independent measurements. ${ }^{\# \#} \mathrm{P}<0.001$, indicates a significant difference between $\mathrm{ST}+\mathrm{RA}$ and $\mathrm{U}+\mathrm{ST}+\mathrm{RA}$.

MEK/ERK activation is required for the enhanced effect of staurosporine on ATRA-induced granulocytic differentiation and the upregulation of $C / E B P S$. Having validated the activation of MEK/ERK by staurosporine, we next ascertained whether the MEK/ERK signaling pathway was required for staurosporine-enhanced ATRA-induced granulocytic differentiation in U937 cells. Cells were treated with $10 \mu \mathrm{M}$ U0126, a specific inhibitor of MEK for $1 \mathrm{~h}$ prior to the other treatments. The effectiveness of U0126 was assessed by ERK1/2 phosphorylation. U0126 did suppress ERK1/2 activation in the U937 cells following the combined treatment (Fig. 4A). Meanwhile, U0126 partially inhibited differentiation induced by the combination of staurosporine and ATRA. Following
U0126 pretreatment, typical granulocytic differentiated cells with lobed nuclei observed following the combined treatment were displaced by cells with kidney-shaped or round nuclei, which were also presented following ATRA treatment (Fig. 4B). However, U0126 pretreatment barely affected the morphological change with ATRA treatment (Fig. 4B). In addition, following U0126 pretreatment, the increased

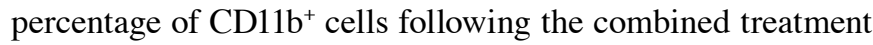
was significantly decreased to a similar level as that following ATRA treatment ( $+\mathrm{ST}+\mathrm{RA}$ compared with $\mathrm{ST}+\mathrm{RA}$, $31.9 \pm 3.1$ vs. $57.3 \pm 2.9 \%, \chi^{2}=1312.8, \mathrm{P}<0.001$; Fig. $4 \mathrm{C}$ and D). Whereas, U0126 only slightly suppressed the population of

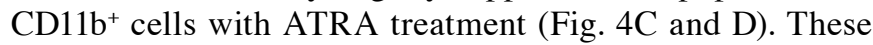




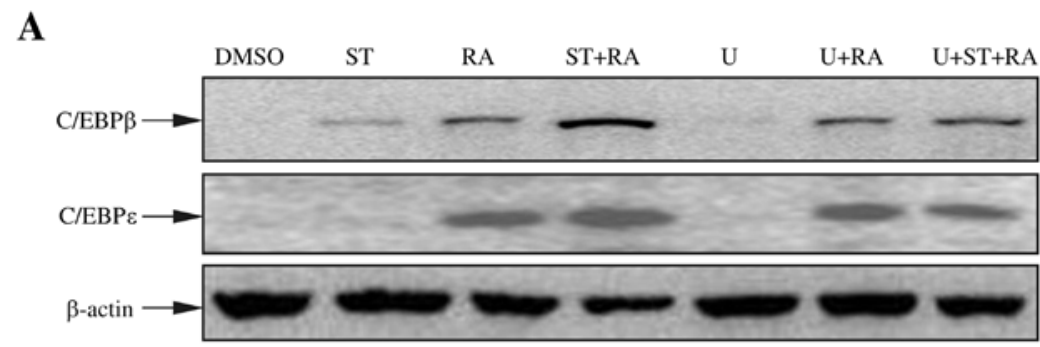

B

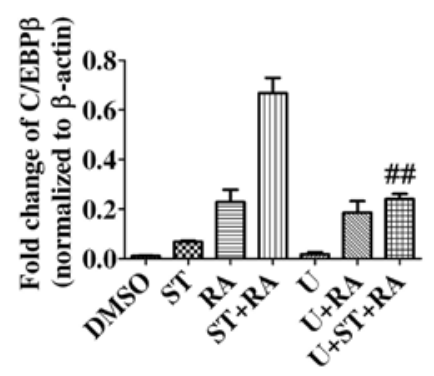

C

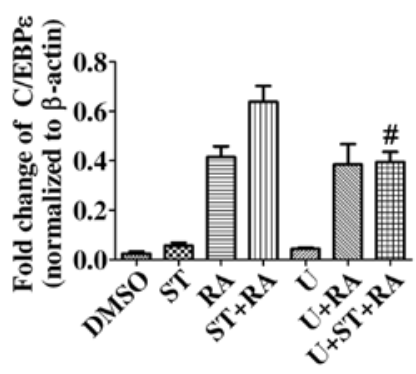

Figure 5. Inhibition of mitogen-activated protein kinase kinase (MEK) activation suppresses the enhanced effect of staurosporine on all-trans retinoic acid (ATRA) upregulated protein levels of CCAAT/enhancer-binding proteins (C/EBPs). Cells were exposed to $10 \mu \mathrm{M}$ U0126 for $1 \mathrm{~h}$ prior to other treatments. (A) The protein levels of C/EBP $\beta$ and C/EBP $\varepsilon$ in U937 cells with the indicated drugs for $24 \mathrm{~h}$ was determined by western blot analysis. Expression of $\beta$-actin was assessed as internal control. (B and C) Quantitated analysis of C/EBP $\beta$ and C/EBP $\varepsilon$ was expressed as protein/ $\beta$-actin. The data are expressed as mean \pm SD of three experiments. ${ }^{\#} \mathrm{P}<0.05,{ }^{\# \#} \mathrm{P}<0.01$, indicates a significant difference between $\mathrm{ST}+\mathrm{RA}$ and $\mathrm{U}+\mathrm{ST}+\mathrm{RA}$.

results excluded the effect of the MEK/ERK signaling pathway on ATRA-triggered differentiation but highlighted its major role in the enhanced effect of staurosporine on ATRA-induced granulocytic differentiation in U937 cells.

Consistent with cell differentiation, U0126 pretreatment attenuated the combined treatment-enhanced C/EBP $\beta$ and C/EBPe protein levels to a similar level of that following ATRA treatment. However, the increased protein levels of $\mathrm{C} / \mathrm{EBP} \beta$ and C/EBPE following ATRA treatment were not altered in the presence of U0126 (Fig. 5). Therefore, staurosporine-enhanced upregulation of C/EBP $\beta$ and C/EBPE following ATRA treatment was mediated by the MEK/ERK signaling pathway.

\section{Discussion}

In the present study, we first demonstrated that staurosporine enhanced ATRA-induced granulocytic differentiation in U937 cells. A high concentration of staurosporine $(1 \mu \mathrm{M})$ was reported to induce necroptotic cell death while a relatively lower concentration (100 nM staurosporine) was found to activate rapid homotypic intercellular adhesion of U937 cells $(27,28)$. To the best of our knowledge, this is the first study to show that very low concentrations of staurosporine exhibit synergism with ATRA to promote granulocytic differentiation in U937 cells. However, the combination of staurosporine and ATRA did not induce differentiation in ATRA-unresponsive cell lines K562 and Kasumi. It was also previously shown that the same combined treatment synergized to trigger differentiation in ATRA-resistant APL cell lines NB4-R1 and NB4-R2 (16). Although NB4-R1 and NB4-R2 cell lines were regarded as ATRA-resistant cell lines, they are not completely unresponsive to ATRA. They are just poorly sensitive to ATRA, that is, ATRA slightly increased the content of $\mathrm{CD}_{11 \mathrm{~b}^{+} \text {cells accom- }}$ panied by some morphologically partial differentiation cells in these two cell lines (16). Meanwhile, $5 \mathrm{nM}$ staurosporine also achieved the similar enhanced effect in ATRA-sensitive HL-60 cells (15). Therefore, it was suggested that staurosporine may only be able to enhance ATRA-promoted differentiation but not to restore ATRA sensitivity.

Staurosporine is a potent but non-selective PKC inhibitor. Some PKC isoforms regulate granulocytic differentiation, that is, PKC- $\alpha$ was suggested to negatively modulate terminal neutrophil differentiation while activated PKC- $\delta$ resulted in ATRA resistance in APL cells $(29,30)$. Thus, we first determined the role of PKC in the combination of staurosporine and ATRA in U937 cells. Two nanomoles of staurosporine, which was used in this study, did not suppress PKC activity. However, being a PKC inhibitor, in concentrations of $10 \mathrm{nM}$ or higher, staurosporine did inhibit PKC activity in the U937 cells. Since the $\mathrm{IC}_{50}$ value of staurosporine, which was $2.7 \mathrm{nM}$, was tested in isolated enzyme, it was possible that much higher concentrations of staurosporine were required to suppress PKC activity in the whole cell system. In further study, we used other selective PKC inhibitors, whose inhibition spectrum covered all the PKC isoforms expressed in U937 cells. However, it was confirmed that they all failed to enhance ATRA-induced granulocytic differentiation in U937 cells. Therefore, staurosporine-enhanced ATRA-induced granulocytic differentiation in U937 cells may be independent of PKC. Some other biological effects of staurosporine were also reported to be PKC-independent (31-35).

To further survey the possible mechanisms of the enhanced effect of staurosporine on ATRA-induced differentiation in U937 cells, due to sparse information regarding the mechanisms of ATRA-triggered differentiation in U937 cells, we focused on certain proteins or signaling pathways involved in granulocytic differentiation. Although an abundance of literature has highlighted the important role of the MEK/ERK signaling pathway in promoting the proliferation and survival of myeloid leukemia cells, rapid and sustained activation of 
MEK/ERK is also required for myeloid differentiation (22-26). In addition, $100 \mathrm{nM}$ staurosporine was demonstrated to activate ERK in U937 cells (28). In the present study, staurosporine but not ATRA activated the MEK/ERK signaling pathway and the blockade of MEK activation inhibited staurosporine-enhanced differentiation in the U937 cells. Meanwhile, consistent with the fact that no MEK/ERK activation was detected following ATRA treatment, inhibition of MEK activation barely affected ATRA-induced differentiation. Therefore, it was concluded that MEK/ERK activation was required for the enhanced effect of staurosporine on ATRA-induced granulocytic differentiation in U937 cells.

The protein levels of $\mathrm{C} / \mathrm{EBP} \beta$ and $\mathrm{C} / \mathrm{EBP} \varepsilon$ were shown to be increased following ATRA treatment in U937 cells. Accompanied by the enhanced effect of staurosporine on ATRA-induced granulocytic differentiation, the upregulation of these two proteins was also elevated by the addition of staurosporine to the ATRA treatment. Meanwhile, although staurosporine activated MEK/ERK, it did not significantly promote the expression of $\mathrm{C} / \mathrm{EBP} \beta$ and $\mathrm{C} / \mathrm{EBP} \varepsilon$ as well as the differentiation in U937 cells. Hence, it was suggested that the increased protein levels of $\mathrm{C} / \mathrm{EBP} \beta$ and $\mathrm{C} / \mathrm{EBP} \varepsilon$ are associated with differentiation in this system. Interestingly, further study confirmed that the inhibition of MEK activation suppressed the enhanced effect of staurosporine not only on ATRA-induced differentiation but also on the upregulation of protein levels of $\mathrm{C} / \mathrm{EBP} \beta$ and $\mathrm{C} / \mathrm{EBP} \varepsilon$. Thus, the enhanced effect of staurosporine on ATRA-induced granulocytic differentiation was modulated by MEK/ERK-mediated upregulation of $\mathrm{C} / \mathrm{EBP} \beta$ and $\mathrm{C} / \mathrm{EBP} \varepsilon$. Being the downstream target of the MEK/ERK signaling pathway, the expression as well as the transcription activity of C/EBP $\beta$ was modulated by MEK/ERK (36-40). Moreover, in ATRA-treated APL cells, C/EBP $\beta$ was demonstrated to promote the expression of $\mathrm{C} / \mathrm{EBP \varepsilon}$ (20). Hence, there may exist an MEK-C/EBP $\beta-\mathrm{C} / \mathrm{EBP} \varepsilon$ cascade in the enhanced effect of staurosporine on ATRA-induced granulocytic differentiation in U937 cells.

In conclusion, staurosporine synergized with ATRA to promote granulocytic differentiation in poorly ATRA-sensitive U937 cells but not in ATRA unresponsive K562 and Kasumi cells. It was implicated that such a combination may be a potential therapeutic strategy for various subtypes of AML with poor sensitivity to ATRA. Staurosporine enhanced ATRA-induced granulocytic differentiation in U937 cells via MEK/ERK-mediated modulation of the protein level of $\mathrm{C} /$ EBPs. Hence, stimulation of the MEK/ERK signaling pathway or upregulation of $\mathrm{C} / \mathrm{EBPs}$ may be an alternative therapeutic approach for certain subtypes of AML.

\section{Acknowledgements}

The present study was supported by the Natural Science Foundation of Shanghai (13ZR1425400).

\section{References}

1. Wang ES: Treating acute myeloid leukemia in older adults Hematology Am Soc Hematol Educ Program 2014: 14-20, 2014.

2. Ablain $\mathrm{J}$ and de Thé $\mathrm{H}$ : Retinoic acid signaling in cancer: The parable of acute promyelocytic leukemia. Int J Cancer 135: 2262-2272, 2014.
3. Göttlicher M, Minucci S, Zhu P, Krämer OH, Schimpf A, Giavara S, Sleeman JP, Lo Coco F, Nervi C, Pelicci PG, et al: Valproic acid defines a novel class of HDAC inhibitors inducing differentiation of transformed cells. EMBO J 20: 6969-6978, 2001.

4. Tassara M, Döhner K, Brossart P, Held G, Götze K, Horst HA, Ringhoffer M, Köhne CH, Kremers S, Raghavachar A, et al: Valproic acid in combination with all-trans retinoic acid and intensive therapy for acute myeloid leukemia in older patients. Blood 123: 4027-4036, 2014.

5. Bug G, Ritter M, Wassmann B, Schoch C, Heinzel T, Schwarz K, Romanski A, Kramer OH, Kampfmann M, Hoelzer D, et al: Clinical trial of valproic acid and all-trans retinoic acid in patients with poor-risk acute myeloid leukemia. Cancer 104: 2717-2725, 2005.

6. Kuendgen A, Schmid M, Schlenk R, Knipp S, Hildebrandt B, Steidl C, Germing U, Haas R, Dohner H and Gattermann N: The histone deacetylase (HDAC) inhibitor valproic acid as monotherapy or in combination with all-trans retinoic acid in patients with acute myeloid leukemia. Cancer 106: 112-119, 2006.

7. Schenk T, Chen WC, Göllner S, Howell L, Jin L, Hebestreit K, Klein HU, Popescu AC, Burnett A, Mills K, et al: Inhibition of the LSD1 (KDM1A) demethylase reactivates the all-trans-retinoic acid differentiation pathway in acute myeloid leukemia. Nat Med 18: 605-611, 2012.

8. Ying M, Zhou X, Zhong L, Lin N, Jing H, Luo P, Yang X, Song H, Yang B and He Q: Bortezomib sensitizes human acute myeloid leukemia cells to all-trans-retinoic acid-induced differentiation by modifying the RAR $\alpha /$ STAT1 axis. Mol Cancer Ther 12: 195-206, 2013.

9. Gianni' M, Boldetti A, Guarnaccia V, Rambaldi A, Parrella E, Raska I Jr, Rochette-Egly C, Del Sal G, Rustighi A, Terao M, et al: Inhibition of the peptidyl-prolyl-isomerase Pin1 enhances the responses of acute myeloid leukemia cells to retinoic acid via stabilization of RARalpha and PML-RARalpha. Cancer Res 69: 1016-1026, 2009.

10. Omura S, Sasaki Y, Iwai Y and Takeshima H: Staurosporine, a potentially important gift from a microorganism. J Antibiot (Tokyo) 48: 535-548, 1995.

11. Yoo CB, Yun SM, Jo C and Koh YH: $\gamma$-Secretase-dependent cleavage of E-cadherin by staurosporine in breast cancer cells. Cell Commun Adhes 19: 11-16, 2012.

12. Mollereau C, Zajac JM and Roumy M: Staurosporine differentiation of $\mathrm{NPFF}_{2}$ receptor-transfected SH-SY5Y neuroblastoma cells induces selectivity of NPFF activity towards opioid receptors. Peptides 28: 1125-1128, 2007.

13. Zhao C, Yin P, Mei C, Li N, Yao W, Li X, Qi J, Fan K, Li Z, Wang L, et al: Down-regulation of DNA methyltransferase 3B in staurosporine-induced apoptosis and its mechanism in human hepatocarcinoma cell lines. Mol Cell Biochem 376: 111-119, 2013.

14. Shimizu T, Okayama A, Inoue T and Takeda K: Analysis of gene expression during staurosporine-induced neuronal differentiation of human prostate cancer cells. Oncol Rep 14: 441-448, 2005.

15. Okazaki T, Kato Y, Mochizuki T, Tashima M, Sawada H and Uchino H: Staurosporine, a novel protein kinase inhibitor, enhances HL-60-cell differentiation induced by various compounds. Exp Hematol 16: 42-48, 1988.

16. Ge DZ, Sheng Y and Cai X: Combined staurosporine and retinoic acid induces differentiation in retinoic acid resistant acute promyelocytic leukemia cell lines. Sci Rep 4: 4821, 2014.

17. Kiley SC and Parker PJ: Differential localization of protein kinase C isozymes in U937 cells: Evidence for distinct isozyme functions during monocyte differentiation. J Cell Sci 108: 1003-1016, 1995.

18. Scott LM, Civin CI, Rorth P and Friedman AD: A novel temporal expression pattern of three C/EBP family members in differentiating myelomonocytic cells. Blood 80: 1725-1735, 1992.

19. Lekstrom-Himes JA: The role of C/EBP(epsilon) in the terminal stages of granulocyte differentiation. Stem Cells 19: 125-133, 2001.

20. Duprez E, Wagner K, Koch H and Tenen DG: C/EBPbeta: A major PML-RARA-responsive gene in retinoic acid-induced differentiation of APL cells. EMBO J 22: 5806-5816, 2003.

21. Truong BT, Lee YJ, Lodie TA, Park DJ, Perrotti D, Watanabe N, Koeffler HP, Nakajima H, Tenen DG and Kogan SC: CCAAT/Enhancer binding proteins repress the leukemic phenotype of acute myeloid leukemia. Blood 101: 1141-1148, 2003. 
22. Miranda MB, McGuire TF and Johnson DE: Importance of MEK-1/-2 signaling in monocytic and granulocytic differentiation of myeloid cell lines. Leukemia 16: 683-692, 2002.

23. Gobert Gosse S, Bourgin C, Liu WQ, Garbay C and Mouchiroud G: M-CSF stimulated differentiation requires persistent MEK activity and MAPK phosphorylation independent of Grb2-Sos association and phosphatidylinositol 3-kinase activity. Cell Signal 17: 1352-1362, 2005.

24. Miranda MB, Xu H, Torchia JA and Johnson DE: Cytokineinduced myeloid differentiation is dependent on activation of the MEK/ERK pathway. Leuk Res 29: 1293-1306, 2005.

25. Barbarroja N, Siendones E, Torres LA, Luque MJ, Martinez JM, Dorado G, Velasco F, Torres A and López-Pedrera C: MEK inhibition induces caspases activation, differentiation blockade and PML/RARalpha degradation in acute promyelocytic leukaemia. Br J Haematol 142: 27-35, 2008

26. Milella M, Konopleva M, Precupanu CM, Tabe Y, Ricciardi MR, Gregorj C, Collins SJ, Carter BZ, D'Angelo C, Petrucci MT, et al: MEK blockade converts AML differentiating response to retinoids into extensive apoptosis. Blood 109: 2121-2129, 2007.

27. Dunai ZA, Imre G, Barna G, Korcsmaros T, Petak I, Bauer PI and Mihalik R: Staurosporine induces necroptotic cell death under caspase-compromised conditions in U937 cells. PLoS One 7: e41945, 2012.

28. Cho JY, Katz DR and Chain BM: Staurosporine induces rapid homotypic intercellular adhesion of U937 cells via multiple kinase activation. Br J Pharmacol 140: 269-276, 2003.

29. Devalia V, Thomas NS, Roberts PJ, Jones HM and Linch DC: Down-regulation of human protein kinase $\mathrm{C}$ alpha is associated with terminal neutrophil differentiation. Blood 80: 68-76, 1992.

30. McNamara S, Nichol JN, Wang H and Miller WH Jr: Targeting PKC delta-mediated topoisomerase II beta overexpression subverts the differentiation block in a retinoic acid-resistant APL cell line. Leukemia 24: 729-739, 2010.

31. Ko JH, Park WS and Earm YE: The protein kinase inhibitor, staurosporine, inhibits L-type $\mathrm{Ca}^{2+}$ current in rabbit atria myocytes. Biochem Biophys Res Commun 329: 531-537, 2005.
32. Park WS, Son YK, Han J, Kim N, Ko JH, Bae YM and Earm YE: Staurosporine inhibits voltage-dependent $\mathrm{K}^{+}$current through a $\mathrm{PKC}$-independent mechanism in isolated coronary arterial smooth muscle cells. J Cardiovasc Pharmacol 45: 260-269, 2005.

33. Yagi Y, Sotani T, Nagao T, Horio T, Yamamoto I and Gohda E: Induction by staurosporine of hepatocyte growth factor production in human skin fibroblasts independent of protein kinase inhibition. Biochem Pharmacol 66: 1797-1808, 2003

34. Tabakman R, Lazarovici P, Matsuda Y, Brodie C and Ovadia H: Protein kinase $\mathrm{C}$-independent selective induction of nitric oxide synthase activity in rat alveolar macrophages by staurosporine. Nitric Oxide 2: 250-258, 1998.

35. Sowa G and Przewłocki R: Enhancing effect of staurosporine on NO production in rat peritoneal macrophages via a protein kinase C-independent mechanism. Br J Pharmacol 116: 1711-1712, 1995.

36. Davis RJ: Transcriptional regulation by MAP kinases. Mol Reprod Dev 42: 459-467, 1995.

37. Lu J, Wu DM, Zheng YL, Hu B, Cheng W, Zhang ZF and Li MQ: Troxerutin counteracts domoic acid-induced memory deficits in mice by inhibiting CCAAT/enhancer binding protein $\beta$-mediated inflammatory response and oxidative stress. J Immunol 190: 3466-3479, 2013.

38. Alam M, Ahmad R, Rajabi H, Kharbanda A and Kufe D: MUC1-C oncoprotein activates $\mathrm{ERK} \rightarrow \mathrm{C} / \mathrm{EBP} \beta$ signaling and induction of aldehyde dehydrogenase $1 \mathrm{~A} 1$ in breast cancer cells J Biol Chem 288: 30892-30903, 2013.

39. Piwien Pilipuk G, Galigniana MD and Schwartz J: Subnuclear localization of C/EBP beta is regulated by growth hormone and dependent on MAPK. J Biol Chem 278: 35668-35677, 2003.

40. Park BH, Qiang L and Farmer SR: Phosphorylation of C/EBPbeta at a consensus extracellular signal-regulated kinase/glycogen synthase kinase 3 site is required for the induction of adiponectin gene expression during the differentiation of mouse fibroblasts into adipocytes. Mol Cell Biol 24: 8671-8680, 2004. 